\title{
Chemotherapy-Induced Alopecia
}

\section{Journal of}

Clinical \& Investigative Dermatology

\author{
Alexandra C Villasante ${ }^{1}$, Ingrid Herskovitz ${ }^{1}$, Lucia \\ M Mauro ${ }^{1,2}$ and Joaquin J Jimenez ${ }^{1,2 *}$ \\ ${ }^{1}$ Department of Dermatology and Cutaneous Surgery, University of \\ Miami Miller School of Medicine, USA \\ ${ }^{2}$ Department of Biochemistry and Molecular Biology, University of \\ Miami Miller School of Medicine, USA
}

*Address for Correspondence

Joaquin J Jimenez, University of Miami Miller School of Medicine, 1600 NW 10th venue, RMSB, Room 2023A, Miami, FL 33136, USA, Tel: 305-2436586; Fax: 1-305-243-6191; E-mail: j.jimenez@med.miami.edu

\section{Submission: 03 April 2014}

Accepted: 02 June 2014

Published: 09 June 2014

Reviewed \& Approved by: Dr. Nihal Ahmad, Professor in Department of Dermatology at the University of Wisconsin, USA

the experience of chemotherapy-induced alopecia (CIA) as more traumatic than actually having cancer [7].

CIA has been found to alter body image, self-identity, and selfconfidence [1-3,14,17-19]. After CIA, 73.3\% of patients felt less selfconfident than they did before [3]. The more severe the degree of alopecia, the lower the psychological wellbeing of the patient [14]. A distress scale for breast cancer patients with CIA was recently developed [19]; patients with higher reported levels of distress from CIA had a greater incidence of depression [20]. Even after regrowth of hair, patients do not necessarily reassume their old identity [21]. Patients with recurrent disease were found to report higher distress associated with hair loss compared to patients with newly diagnosed disease [4]. Microscopic and Clinical Characteristics of CIA

Histologic features that characterize chemotherapy-induced abnormalities, or follicular dystrophy, include: disruption of melanin accumulation, irregular banding patterns of the hair shaft, an irregular follicular diameter, a widened hair canal, and distortion of the hair follicle [22]. The cross sectional diameter of regrown hair is smaller after CIA [23]. Furthermore, hairs shed due to CIA have characteristic features when examined trichoscopically, including proximal hair shaft constriction, leading to "Pohl-Pinkus constrictions" and "exclamation mark hair" [24,25].

Whether a patient will develop CIA and to what extent depend chiefly on the drug regimen administered and on the dosage [26]. Drugs found to produce severe alopecia with high incidence include alkylating agents (eg. cyclophosphamide, ifosfamide); anthracyclines (eg. doxorubicin, duanorubicin); antimicrotubule agents (eg. docetaxel and paclitaxel); and topoisomerase inhibitors (eg. etoposide) [26-29]. Combination regimens with two or more agents are associated with greater incidence and severity of alopecia [26].

In CIA, hair loss begins shortly after the initiation of chemotherapy and becomes maximal after 6 weeks [30]. CIA becomes noticeable once approximately $50 \%$ of hairs are lost [27-29]. Regrown hair is often initially of a different texture, color, and density [27-29]. Hair growth returns to its normal rate within three months of chemotherapy 
cessation [30]. CIA was previously thought to be a diffuse alopecia, but instead CIA is characterized by distinct patterns of hair loss that vary by sex [31]. Men lose hair in the Hamilton-Norwood pattern, while women lose hair in the Ludwig pattern [31-35].

There are various grading scales for CIA, including the WHO classification (1981), the Common Terminology Criteria for Adverse Events (CTCAE) (2006, revised in 2010), the Olsen CIA scale (2007), and the Multinational Association of Supportive Care in Cancer (MASCC) (2010) [36]. The WHO and CTCAE 2006 scales use qualitative while the other scales assign percentages of hair loss, and these distinctions are based on approximate clinical assessments [36].

Though CIA is usually reversible, cases of permanent alopecia have been reported [37-39]. Permanent CIA occurs in the rare event that the stem cells in the bulge, which cycle at a slower rate than matrix keratinocytes, are not protected from chemotherapeutic insult $[40,41]$. Permanent CIA is usually seen after administration of a preconditioning chemotherapeutic regimen before bone marrow transplantation; typical preconditioning regimens include high-dose busulfan with cyclophosphamide or etoposide [37-39]. A recent review found that $12 \%$ of pediatric patients who had undergone highdose preconditioning chemotherapy followed by hematopoietic stem cell transplantation developed permanent alopecia [42]. Permanent CIA is not seen exclusively in association with bone marrow transplantation; it has also been reported after treatment for solid organ cancers, for example with standard breast cancer regimens $[37,39,43]$. Histologically, permanent alopecia is characterized by: an increased ratio of vellus to terminal hairs, an increased ratio of telogen to anagen follicles, and the appearance of basaloid epithelium without evidence of scarring or inflammation $[37,39]$.

\section{The Pathophysiology of CIA}

There are various mechanisms of CIA, including those that interrupt mitosis, impair metabolic processes, induce cellular damage response pathways, and/or lead to hair matrix cell apoptosis [44]. Various molecular pathways have been implicated in the development of CIA, such as those involving tumor suppressor p53 [45], the p53 mediator and target Fas [13-15, 45-47], and apoptosis regulator Bcl-2 $[45,48,49]$. Some chemotherapeutic agents, for example doxorubicin, have been shown to damage the hair-follicle vasculature [50] and the sebaceous gland [51]. Others such as cyclophosphamide cause oxidative damage to the follicular pigmentary unit, leading to changes in hair color [22].

HFs most susceptible to CIA are mature, pigmented, late-anagen follicles whose matrix keratinocytes have a rapid rate of proliferation [31,52]. A human scalp HF, which cycles continually, may at any particular moment be in active proliferation (anagen), apoptosisdriven involution (catagen), or relative quiescence (telogen) [52,53]. Of the 100,000 terminal HFs found on the adult human scalp, approximately $90 \%$ are in anagen at any given time [54,55]. At the start of each anagen, a population of stem cells from the bulge region, stimulated by factors in the nearby dermal papilla, forms new matrix keratinocytes [56]. During late anagen, these rapidly proliferating keratinocytes terminally differentiate and are compacted into a fiber, the outwardly moving hair shaft [52]. CIA is, then, largely an anagen effluvium [31]. Telogen effluvium, in which resting HFs are shed, has also been reported in CIA, and usually occurs with lower toxicity drugs such as methotrexate and 5-fluorouracil [24].

Based on observations in animal models, there are two main pathways of cellular damage in CIA: "dystrophic anagen" (DysA) and "dystrophic catagen" (DysC) [44,57]. The DysA pathway is induced by lower dose, lower toxicity antineoplastic agents. In the DysA pathway, after insult to the HF there occurs a prolongation of the present anagen, during which time the hair shaft continues to grow but has severely abnormal pigmentation. Subsequently, the HF undergoes an extremely shortened telogen and the hair shaft is shed. Next, a second anagen occurs where the hair shaft is phenotypically normal. The DysC pathway, on the other hand, is induced by higher dose, higher toxicity agents. These more damaging chemotherapeutic insults promptly drive the HF to catagen through a shortened telogen, and the hair shaft is shed. Concurrently, follicular melanogenesis ceases. Hair shedding is followed by a new anagen phase, during which time a normally pigmented hair shaft grows. The DysC pathway is characterized by earlier emergence of phenotypically normal regrown hair in comparison to the DysA [44,57]. Various treatment modalities studied have aimed to take advantage of this phenomenon $[44,57,58]$.

\section{Therapy for CIA}

Scalp Tourniquet and Scalp Cooling: The first method developed for the prevention of CIA was the scalp tourniquet, which consisted of a blood pressure cuff inflated around the scalp providing mechanical obstruction to scalp perfusion [59-63]. Subsequently, scalp cooling was developed, beginning with Dean et al. who wrapped plastic bags of crushed ice around patients' heads with a bandage, forming an "ice turban" [64]. The ice turban was placed five minutes before chemotherapy was administered and was left on for the first 30 minutes of treatment; it was well-tolerated, and its effectiveness decreased with increased drug dosage and with each round of chemotherapy [9]. Later, caps were developed utilizing cold air [65], cold gel [66], or glycol-based fluids [67]. Various cooling times and scalp temperatures have been used; the goal is to achieve a scalp temperature of $<22^{\circ} \mathrm{C}$, which can be done with a preset coolant temperature of $3-8^{\circ} \mathrm{C}$ [68]. Scalp cooling works by promoting local vasoconstriction, decreasing the uptake of cytotoxic drugs by HFs, and reducing local biochemical activities [9]. Currently, scalp cooling methods are not as widely available in the United States as in Europe because they are not approved by the Food and Drug Administration [26]. There are presently two ongoing clinical trials for scalp cooling therapies in the US $[69,70]$.

Effectiveness of scalp cooling has been reported from $52 \%$ to $83 \%$ after administration of single-agent chemotherapy [66,71-78]. In one Dutch study, after a single round of chemotherapy, $81 \%$ of 53 scalpcooled patients did not require a wig or head covering compared to $27 \%$ of 15 controls ( $p=0.0002$ ) [79]. In another study, during the last round of chemotherapy, $50 \%$ of 1,411 scalp-cooled patients did not need to wear a wig or head covering [80]. Effectiveness of scalpcooling is much decreased in patients undergoing chemotherapy with multiple agents. Scalp cooling fails to protect against certain chemotherapeutic classes, such as the taxanes [71,72].

The major concern with scalp cooling is that, with this method, potential scalp metastases might also be protected from the cytotoxic 
Citation: Villasante AC, Herskovitz I, Mauro LM, Jimenez JJ. Chemotherapy-Induced Alopecia. J Clin Investigat Dermatol. 2014;2(2): 8.

ISSN: 2373-1044

Table 1: Therapies for CIA tested in animal models.

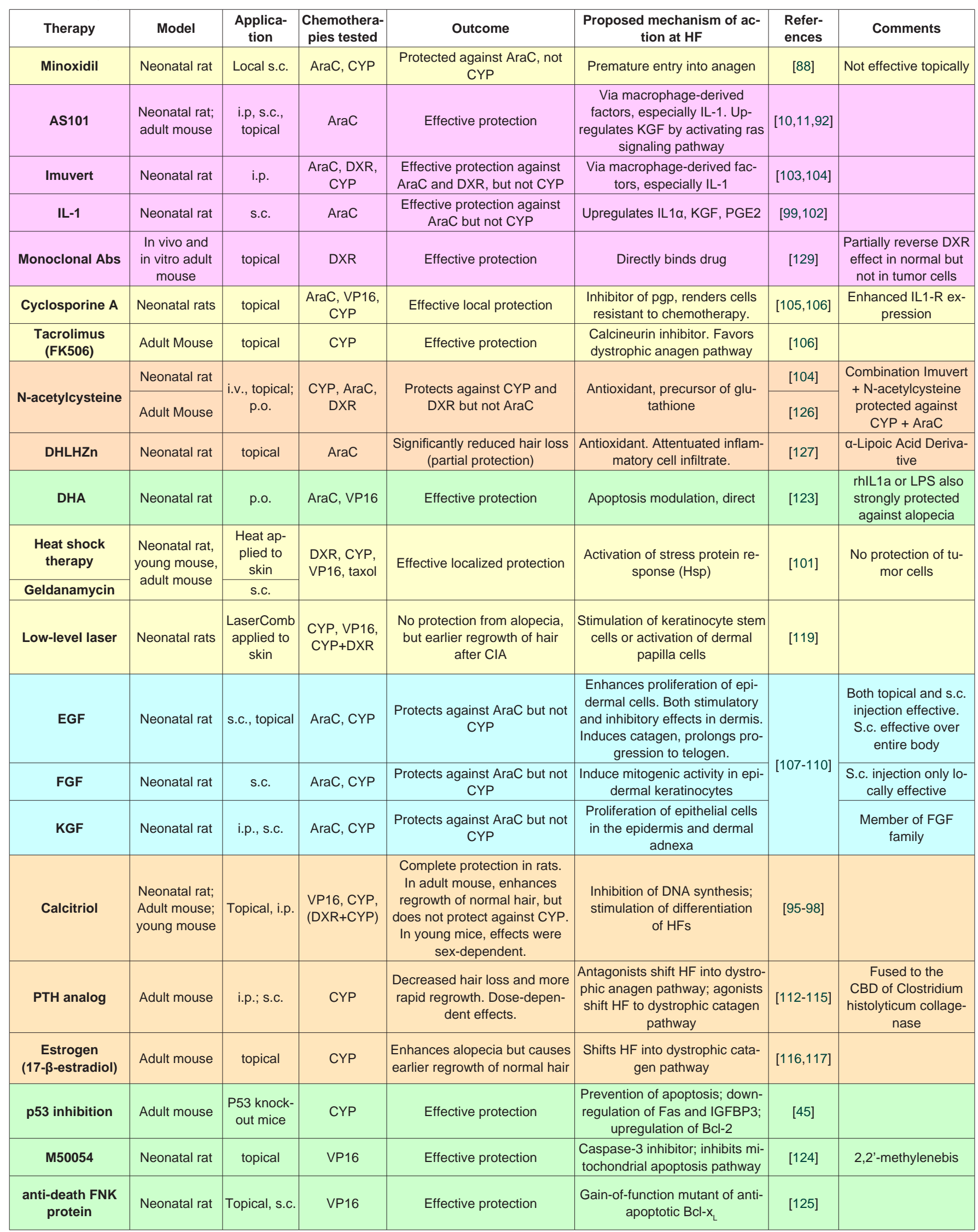




\begin{tabular}{|c|c|c|c|c|c|c|c|}
\hline Shh & Adult mouse & \begin{tabular}{|} 
Adenovirus \\
vector by \\
intradermal \\
injection
\end{tabular} & CYP & $\begin{array}{l}\text { Does not protect; accelerates } \\
\text { regrowth }\end{array}$ & Accelerates initiation of anagen & [121] & \\
\hline Heparanase & Adult mouse & $\begin{array}{l}\text { Transgenic } \\
\text { mice }\end{array}$ & CYP & $\begin{array}{l}\text { Does not protect; accelerates } \\
\text { regrowth }\end{array}$ & $\begin{array}{l}\text { Release of growth factors from } \\
\text { ECM. Modulate hair cycling }\end{array}$ & [118] & $\begin{array}{l}\text { Endoglycosidase } \\
\text { cleaves heparan sul- } \\
\text { fate of ECM }\end{array}$ \\
\hline Oral zinc & Adult mouse & $\begin{array}{l}\text { p.o. (in } \\
\text { water) }\end{array}$ & CYP & $\begin{array}{l}\text { Does not protect; accelerates } \\
\text { regrowth of normally pig- } \\
\text { mented hair }\end{array}$ & $\begin{array}{c}\text { Prolongs catagen (dystrophic } \\
\text { catagen pathway) }\end{array}$ & [120] & \\
\hline $\begin{array}{l}\text { L-cystine + Vita- } \\
\quad \min B 6\end{array}$ & Adult mouse & p.o. & DXR & Effective protection & $\begin{array}{l}\text { Nutrients necessary for hair } \\
\text { growth. L-cystine may inhibit } \\
\text { apoptosis. B6 may be antioxi- } \\
\text { dant }\end{array}$ & [128] & \\
\hline$\alpha-\mathrm{MSH}$ & $\begin{array}{l}\text { Human in vitro } \\
\text { model }\end{array}$ & Cell culture & $\begin{array}{l}\text { CYP metabo- } \\
\text { lite }(4-\mathrm{HC})\end{array}$ & Moderate protection & $\begin{array}{c}\text { Reduced melanin clumping, } \\
\text { reduced apoptosis. Upregulated } \\
\text { cytoprotective enzyme heme } \\
\text { oxygenase-1 }\end{array}$ & [122] & \\
\hline
\end{tabular}

VP16: Etoposide; DXR: doxorubicin; CYP: cyclophosphamide; AraC: cytarabine; 5FU: fluorouracil; MTX: Methotrexate; VLB: vinblastine

i.p.: intraperitoneal injection; s.c.: subcutaneous injection; i.v.: intravenous injection; p.o.: per oral;

rIIL1a: Recombinant human interleukin-1-alpha; DHLHZn: Sodium Zinc Dihydrolipoyl-histidinate; pgp: P-glycoprotein; IGFBP3: insulin-like growth factor-binding protein 3; EGF: epidermal growth factor; FGF: fibroblast growth factor; KGF: keratinocyte growth factor; CBD: collagen

binding domain; 4HC: 4-hydroperoxy-cyclophosphamide; $\alpha-\mathrm{MSH}$ : $\alpha$-melanocyte stimulating hormone; CKD: cyclin-dependent kinase; PTH: parathyroid hormone; DHA: Docosahexanoic acid; Shh: sonic hedgehog; LPS: lipopolysaccharide; ECM: extracellular matrix;

effects of chemotherapy $[9,81-83]$. This concern is especially pressing in hematologic malignancies where the pre-treatment prevalence of scalp metastases is higher [9]. There are a small number of case reports of scalp metastases discovered after scalp cooling in both hematologic $[67,81,82]$ and solid malignancies $[67,72,83,84]$; however, it is not clear whether scalp cooling was causative. The incidence of scalp metastasis was found to be low at 9 out of $2500(0.36 \%)$ in a literature review of scalp cooling in CIA from 1973 to 2003 [9].

Side effects of scalp cooling include headache and coldness, which increase with lower coolant temperature [68]. Psychological side effects include increased distress when scalp cooling is unsuccessful $[75,85]$.

Pharmaceutical therapies for CIA studied in humans: Minoxidil, an antihypertensive vasodilator used to promote hair growth in androgenetic alopecia, failed to protect from CIA in clinical trials $[86,87]$, but did protect in an animal model [88] (Table 1). Minoxidil has, however, shown to induce earlier regrowth of hair after CIA in humans [89]. The mechanism of minoxidil appears to be a reduction of the time in telogen, leading to the premature entry of the HF into anagen [90]. Other proposed actions of minoxidil at the HF include prolongation of anagen, increase in HF size, inhibition of collagen synthesis, stimulation of cell proliferation, and increased synthesis of vascular endothelial growth factor (VEGF) and prostaglandins [91].

The immune modulator AS101 significantly reduced CIA in human trials and provided complete protection against CIA in animal models $[10,11,92]$ (Table 1). Compared to controls, fewer AS101 patients developed severe alopecia, and more were found to have minimal alopecia $[10,11]$. The overall difference between AS101 and control groups was statistically significant in two randomized trials of non-small cell lung cancer patients receiving combination carboplatin and etoposide $[10,11]$. When comparing groups that did not develop any alopecia, however, the difference between AS101 and control groups was not significant in either study [10,11]. Among 44 patients, $26 \%$ in the AS101 group had no alopecia after 3 months compared to $10 \%$ in the control group [10]. Among 58 patients,
$37.2 \%$ vs. $20.4 \%$ showed no alopecia after three months in AS101 vs. control groups [11].

Vitamin D analogs have not yet demonstrated protection against CIA in humans; they have, however, shown effectiveness in animal models [93-98](Table 1). Topical calcitriol (1,25-hydroxyvitamin D) was tested in a phase I human trial using three different administration doses and schedules; all 12 patients in the treatment arm and the 2 patients in the placebo group developed moderate alopecia by days 20-30 post-chemotherapy [93]. Similarly, no difference was detected between topical calcipotriol or vehicle groups in a study of 24 breast cancer patients receiving a regimen of cyclophosphamide, methotrexate, and 5-fluorouracil [24].

Therapies for CIA studied in animal models: There are various animal models for CIA including neonatal rat, adult rat, neonatal mouse, and adult mouse models [44,99-101]. Amongst them, various pharmaceutical therapies have been tested, including growth factors and cytokines, antioxidants, hair cycle modifiers, biologic response modifiers, and apoptosis inhibitors.

AS101 was found to completely protect from CIA in neonatal rats, and the mechanism was proposed to be via macrophagederived cytokines including interleukin-1 (IL-1) [10,11,92]. Immune cell derived factors, including IL-1, are essential to the mechanism several therapies known to protect against CIA in animals, including IL-1 injected intraperitoneally [99,102], biological response modifier Imuvert delivered intraperitoneally [103,104], and topical immunomodulators cyclosporine A and tacrolimus [105,106] (Table 1).

Topical calcitriol has also shown effectiveness in animal models: it protected against CIA in neonatal rats against etoposide, cyclophosphamide, and combination doxorubicin / cyclophosphamide [95,96]. Topical calcitriol did not effectively prevent cyclophosphamide-induced alopecia in C57BL/6 mice, but enhanced regrowth of normal hair [58] and reduced apoptosis in the hair follicle [97]. In BALB/c mice, topical calcitriol did protect against 
cyclophosphamide-induced alopecia, but in a sex-dependent way; the effect was more pronounced in male than in female tumor-free mice, and protection increased with increasing tumor burden in tumorladen female mice [98].

Many studied therapies for CIA ultimately modulate the hair cycle. Some of these therapies protect the HF by inducing a stage in which the HF is less vulnerable to chemotherapy. Some therapies for CIA enhance proliferation of keratinocytes in the epidermis; such therapies include epidermal growth factors (EGF), fibroblast growth factor (FGF), and keratinocyte growth factor (KGF) [107-110] (Table 1). Calcitriol was shown to enhance mitogenesis via the KGF receptor [111]. Others enhance one dystrophic pathway or another-DysA or DysC. Therapies for CIA that are thought to take advantage of hair cycling include: minoxidil [89,105], tacrolimus (FK506) [106], epidermal growth factor (EGF) [107-110], parathyroid hormone agonists and antagonists [112-115], estrogen [116,117], heparanase [118], low-level laser [119], zinc [120], and gene therapy with sonic hedgehog (Shh) [121] (Table 1).

Another strategy to protect the HF from cytotoxic chemotherapy is inhibition of apoptosis. Whether directly or indirectly, this therapeutic strategy occurs with p53 inhibition [45], a-melanocyte stimulating hormone [122], L-cystindocosahexanoic acid (DHA) [123], caspase-3 inhibition (eg. M50054) [124], and the anti-death FNK protein [125] (Table 1). Antioxidants N-acetylcysteine [95, 126], sodium zinc dihydroyl-histidinate [127], and combination L-cystine plus vitamin B6 [128] have also shown protection in animals (Table $1)$.

In this regard, activating intracellular mechanisms of resistance to toxins is a strategy that could protect against a broad spectrum of chemotherapeutics, as opposed to therapies that protect against only one type of drug like monoclonal antibodies to doxorubicin [129]. Heat shock therapy, which activates a stress protein response, was shown to protect against CIA by four different classes of chemotherapy in three different animal models, and it exhibited no protection of tumor cells [101]. One proposed intracellular target is the ATPbinding cassette $(\mathrm{ABC})$ transporter, which was found to reduce the accumulation of chemotherapeutic drugs, thereby enhancing cellular drug resistance [130].

\section{E. Strategies for coping with CIA}

Because there are no therapies yet proven to effectively prevent CIA in humans besides scalp cooling, patients must employ strategies to cope with hair loss. Anticipatory counseling, psychological support, and head coverings are the mainstays of management [2629]. Some psychosocial tools include anticipating hair loss, coming to terms with the inevitability of it, becoming ready, and taking control [131]. Even if expected, however, alopecia is a traumatic event for patients [6].

Camoflauge techniques, such as wearing a wig, scarf, hat, or other head covering, are central in CIA management [26-29]. Patients can be given a prescription for an "extra-cranial prosthesis" by their oncologist and sometimes their health insurance, if applicable, will cover part or all of the cost of the wig. Patients should plan for a head covering in advance. These methods will protect the scalp from the elements including sun damage, and they often make it easier for the patient to feel incorporated into social life [26-29]. Patients who use a wig to mask CIA report that their wig provides them with support, akin to a "friend" [6]. They affirm that the wig obscures the appearance of illness thereby facilitating evasion of stigma [6].

Gentle hair care techniques are suggested, such as avoiding physical or chemical trauma to the hair, using a satin pillowcase, and combing the hair gently [26]. Also recommended is shaving the scalp or clipping the hair short prior to chemotherapy administration [2629].

\section{Conclusion}

Chemotherapy-induced alopecia is an important condition that greatly impacts the cancer experience; yet, managing CIA and recognizing its psychosocial impact are not always prioritized within cancer care. No single approach has yielded a definitive therapy for CIA in humans, thus far. After CIA occurs, the mainstays of management are psychosocial support and head covering. Animal models for CIA are vital in our understanding of the pathophysiology of the disorder and in development of a future cure. The ideal pharmacologic therapy for CIA protects the HF from a wide spectrum of chemotherapeutic insults and does not interfere with the activity of chemotherapy on tumor cells. Promising therapeutic mechanistic modalities include hair cycle modulation, apoptosis inhibition, and engagement of growth factors and cytokines. Clinical trials complementary to successful animal studies for CIA are required. Also necessary are further clinical studies documenting the incidence, severity, and course of CIA by chemotherapeutic drug.

\section{References}

1. Freedman TG (1994) Social and cultural dimensions of hair loss in women treated for breast cancer. Cancer Nurs 17: 334-341.

2. Carpenter JS, Brockopp DY (1994) Evaluation of self-esteem of women with cancer receiving chemotherapy. Oncol Nurs Forum 21: 751-757.

3. Munstedt K, Manthey N, Sachsse S, Vahrson H (1997) Changes in selfconcept and body image during alopecia induced cancer chemotherapy. Support Care Cancer 5: 139-143.

4. Sun CC, Bodurka DC, Weaver CB, Rasu R, Wolf JK, et al. (2005) Rankings and symptom assessments of side effects from chemotherapy: insights from experienced patients with ovarian cancer. Support Care Cancer 13: 219-227.

5. Dougherty $L$ (2007) Using nursing diagnoses in prevention and management of chemotherapy-induced alopecia in the cancer patient. Int J Nurs Terminol Classif 18: 142-149.

6. Zannini L, Verderame F, Cucchiara G, Zinna B, Alba A, et al. (2012) 'My wig has been my journey's companion': perceived effects of an aesthetic care programme for Italian women suffering from chemotherapy-induced alopecia. Eur J Cancer Care 21: 650-660.

7. Jayde V, Boughton M, Blomfield P (2013) The experience of chemotherapyinduced alopecia for Australian women with ovarian cancer. Eur J Cancer Care 22(4): 503-0512.

8. Tierney AJ, Taylor J, Closs SJ (1992) Knowledge, expectations and experiences of patients receiving chemotherapy for breast cancer. Scand J Caring Sci 6: 75-80.

9. Grevelman EG, Breed WP (2005) Prevention of chemotherapy-induced hair loss by scalp cooling. Ann Oncol 16(3): 352-358.

10. Sredni B, Albeck M, Tichlet T, Shani A, Shapira J, et al. (1995) Bone marrow sparing and prevention of alopecia by AS101 in non-small-cell lung cancer patients treated with carboplatin and etoposide. J Clin Oncol 13: 2342-53.

11. Sredni B, Xu RH, Albeck M, Gafter U, Gal R, et al. (1996) The protective 
Citation: Villasante AC, Herskovitz I, Mauro LM, Jimenez JJ. Chemotherapy-Induced Alopecia. J Clin Investigat Dermatol. 2014;2(2): 8.

role of the immunomodulator AS101 against chemotherapy- induced alopecia studies on human and animal models. Int J Cancer 65: 97-103.

12. Hilton S, Hunt K, Emslie C, Salinas M, Ziebland S (2008) Have men been overlooked? A comparison of young men and women's experiences of chemotherapy-induced alopecia. Psychooncology 17: 577-583.

13. Rossman S (2004) Cancer and stigma: experience of patients with chemotherapy-induced alopecia. Patient Educ Couns 52: 333-339.

14. Can G, Demir M, Erol O, Aydiner A (2013) A comparison of men and women's experiences of chemotherapy-induced alopecia. Eur J Oncol Nurs 17: 255260.

15. Janelsen MC, Tejani M, Kamen C, Peoples A, Mustian KM, et al. (2013) Current pharmacotherapy for chemotherapy-induced nausea and vomiting in cancer patients. Expert Opin Pharmacother 14: 757-766.

16. Griffin Am, Butow PN, Coates AS, Childs AM, Ellis PM, et al. (1996) On the receiving end $\mathrm{V}$ : Patient perceptions of the side effects of cance chemotherapy in 1993. Ann Oncol 7: 189-195

17. Williams J, Wood C, Cunningham-Warburton P (1999) A narrative study of chemotherapy-induced alopecia. Oncol Nurs Forum 26: 1463-1468.

18. Nolte S, Donnelly J, Kelly S, Conley P, Cobb R (2006) A randomized clinical trial of a videotape intervention for women with chemotherapy-induced alopecia: a gynecologic oncology group study. Oncol Nurs Forum 33: 305311

19. Cho J, Choi EK, Kim IR, Im YH, Park YH, et al. (2014) Development and validation of chemotherapy-induced distress scale (CADS) for breast cancer patients. Ann Oncol 25: 346-351.

20. Choi EK, Kim IR, Chang O, Kang D, Nam SJ, et al. (2014) Impact of chemotherapy-induced alopecia distress on body image, psychosocial wellbeing, and depression in breast cancer patients. Psychooncology.

21. Koszalinski RS, Williams C (2012) Embodying identity in chemotherapy induced alopecia. Perspect Psychiatr Care 48: 116-121.

22. Hendrix S, Handjiski B, Peters EMJ, Paus R (2005) A guide to assessing damage response pathways in the hair follicle: lessons from chyclophosphamide-induced alopecia in mice. J Invest Dermatol 125: 42-51.

23. Linder J, Hillmann K, Blume-Peytavi U, Lademann J, Lux A, et al. (2012) Hai shaft abnormalities after chemotherapy and tamoxifen therapy in patients with breast cancer evaluated by optical coherence tomography. $\mathrm{Br} \mathrm{J}$ Dermato 167: 1272-1278.

24. Bleiker TO, Nicolaou N, Traulsen J, Hutchinson PE (2005) 'Atrophic telogen effluvium' from cytotoxic drugs and a randomized controlled trial to investigate the possible protective effect of pretreatment with a topical vitamin D3 analogue in humans. Br J Dermatol 153: 103-112.

25. Pirmez R, Pineiro-Maceira J, Sodre CT (2013) Exclamation marks and other trichoscopic signs of chemotherapy-induced alopecia. Australas J Dermato 54: 129-132.

26. Chon SY, Champion RW, Geddes ER, Rashid RM (2012) Chemotherapyinduced alopecia. J Am Acad Dermatol 67: e37-47.

27. Trueb RM (2009) Chemotherapy-induced alopecia. Semin Cutan Med Surg 28: $11-14$.

28. Trueb RM (2010) Chemotherapy-induced hair loss. Skin Therapy Lett 2010 15: 5-7.

29. Trueb RM (2010) Chemotherapy-induced alopecia. Curr Opin Support Palliat Care 4: 281-284

30. Kanti V, Nuwayhid R, Lindner J, Hillmann K, Stroux A, et al. (2014) Analysis of quantitative changes in hair growth during treatment with chemotherapy or tamoxifen in patients with breast cancer: a cohort study. Br J Dermatol 170 643-650.

31. Yun SJ, Kim SJ (2007) Hair loss pattern due to chemotherapy-induced anagen effluvium: a cross-sectional observation. Dermatology 215: 36-40.

32. Hamilton JB (1951) Patterned loss of hair in man: types and incidence. Ann
NY Acad Sci 53: 708-723.

33. Norwood OT (1975) Male pattern baldness: classification and incidence. South Med J 68: 1359-1365

34. Ludwig E (1977) Classification of the types of androgenetic alopecia (common baldness) occurring in the female sex. Br J Dermatol 97: 247-254.

35. Olsen EA (2001) Female pattern hair loss. J Am Acad Dermatol 45: S70-80.

36. Yeager CE, Olsen EA (2011) Treatment of chemotherapy-induced alopecia. Dermatol Ther 24: 432-442.

37. Tallon B, Blanchard E, Goldberg LJ (2010) Permanent chemotherapyinduced alopecia: case report and review of the literature. J Am Acad Dermatol 63: 333-336.

38. Miteva M, Misciali C, Fanti PA, Vincenzi C, Romanelli P, et al. (2011) Permanent alopecia after systemic chemotherapy: a clinicopathological study of 10 cases. Am J Dermatopathol 33: 345-350.

39. Palamaras I, Misciali C, Vincenzi C, Robles WS, Tosti A (2011) Permanent chemotherapy-induced alopecia: a review. J Am Acad Dermatol 64: 604-606

40. Lyle S, Christofidou-Solomidou M, Liu Y, Elder DE, Albelda S, et al. (1998) The C8/144B monoclonal antibody recognizes cytokeratin 15 and defines the location of human hair follicle stem cells. J Cell Sci 111: 3179-3188.

41. Cotsarelis G (2006) Gene expression profiling gets to the root of human hair follicle stem cells. J Clin Invest 116: 19-22.

42. Choi M, Kim MS, Park SY, Park GH, Jo SJ, et al. (2014) Clinical characteristics of chemotherapy-induced alopecia in childhood. J Am Acad Dermatol 70: 499-505.

43. Machado M, Moreb JS, Khan SA (2007) Six cases of permanent alopecia after various conditioning regimens commonly used in hematopoietic stem cell transplantation. Bone Marrow Transplant 40: 979-82.

44. Paus R, Haslam IS, Sharov AA, Botchkarev VA (2013) Pathobiology of chemotherapy-induced hair loss. Lancet Oncol 2013; 14: e50-59.

45. Botchkarev VA, Komarova EA, Siebenhaar F, Botchkareva NV, Komarov PG, et al. (2000) p53 is essential for chemotherapy-induced hair loss. Cancer Res 60: 5002-5006.

46. Sharov AA, Li GZ, Palkina TN, Sharova TY, Gilchrest BA, et al. (2003) Fas and c-kit are involved in the control of hair follicle melanocyte apoptosis and migration in chemotherapy-induced hair loss. J Invest Dermatol 120: 27-35.

47. Sharov AA, Siebenhaar F, Sharova TY, Botchkareva NV, Gilchrest BA, et al. (2004) Fas signaling is involved in the control of hair follicle response to chemotherapy. Cancer Res 64: 6266-6270.

48. Muller-Rover S, Rossiter H, Paus R, Handjiski B, Peters EMJ, et al. (2000) Overexpression of $\mathrm{Bcl}-2$ protects from ultraviolet B-induced apoptosis but promotes hair follicle regression and chemotherapy-induced alopecia. Am J Pathol 156: 1395-1405.

49. Luanpitpong $S$, Nimmannit $U$, Chanvorachote $P$, Leonard $S S$ Pongrakhananon V, et al. (2011) Hydroxyl radical mediates cisplatin-induced apoptosis in human hair follicle dermal papilla cells and keratinocytes through Bcl-2-dependent mechanism. Apoptosis 16: 769-782.

50. Amoh Y, Li L, Katsuoka K, Hoffman RM (2007) Chemotherapy targets the hair-follicle vascular network but not the stem cells. J Invest Dermatol 127 $11-15$.

51. Selleri S, Arnaboldi F, Palazzo M, Hussein U, Balsari A, et al. (2005) Caveolin-1 is expressed on multipotent cells of hair follicles and might be involved in their resistance to chemotherapy. Br J Dermatol 153: 506-513.

52. Schneider MR, Schmidt-Ullrich R, Paus R (2009) The hair follicle as a dynamic miniorgan. Curr Biol 19: R132-42.

53. Chase HB (1954) Growth of the Hair. Physiol Rev 34: 113-126.

54. Crounse RG, Van Scott EJ (1960) Changes in scalp hair roots as a measure of toxicity from cancer chemotherapeutic drugs. J Invest Dermatol 35: 83-90.

55. Whiting DA (1996) Chronic telogen effluvium: increased scalp hair shedding 
in middle-aged women. J Am Acad Dermatol 35: 899-906.

56. Wilson C, Cotsarelis G, Wei ZG, Fryer E, Margolis-Fryer J, et al. (1994) Cells within the bulge region of mouse hair follicle transiently proliferate during early anagen: heterogeneity and functional differences of various hair cycles. Differentiation 55: 127-136

57. Paus R, Handjiski B, Eichmuller S, Czarnetzki BM (1994) Chemotherapyinduced alopecia in mice: induction by cyclophosphamide, inhibition by cyclosporine A, and modulation by dexamethasone. Am J Pathol 144: 719734.

58. Paus R, Schilli MB, Handjiski B, Menrad A, Henz BM, et al. (1996) Topical calcitriol enhances normal hair regrowth but does not prevent chemotherapyinduced alopecia in mice. Cancer Res 56: 4438-4443.

59. Simister JM (1966) Alopecia and cytotoxic drugs. Br Med J 2: 1138.

60. Hennessy JD (1966) Letter: alopecia and cytotoxic drugs. BMJ 2: 1138.

61. O'Brien R, Zelson JH, Schwartz AD, Pearson HA (1970) Scalp tourniquet to lessen alopecia after vincristine. N Engl J Med 283:1469.

62. Pesce A, Cassuto JP, Joyner MV, DuJardin P, Audoly P (1978). Scalp tourniquet in the prevention of chemotherapy-induced alopecia. N Engl J Med 298: $1204-1205$

63. Maxwell MB (1980) Scalp tourniquets for chemotherapy-induced alopecia. Am J Nurs 80: 900-903.

64. Dean JC, Salmon SE, Griffith KS (1979) Prevention of doxorubicin-induced hair loss with scalp hypothermia. N Engl J Med 301: 1427-1429.

65. Hillen HFP, Breed WPM, Botman CJ (1990) Scalp cooling by cold air for the prevention of chemotherapy-induced alopecia. Neth J Med 37: 231-235.

66. Vendelbo JL (1985) Scalp hypothermia in the prevention of chemotherapyinduced alopecia. Acta Radiol 24: 113-116.

67. Lemieux J, Desbiens C, Hogue JC (2011) Breast cancer scalp metastasis as first metastatic site after scalp cooling: two cases of occurrence after 7- and 9-year follow-up. Breast Cancer Res Treat 128: 563-536.

68. Ekwall EM, Nygren LM, Gustafsson AO, Sorbe BG (2013) Determination of the most effective cooling temperature for the prevention of chemotherapyinduced alopecia. Mol Clin Oncol 1: 1065-1071.

69. Baylor Breast Cancer Care Center. Scalp Cooling to Prevent Chemo-induced Hair Loss (SCALP). In: ClinicalTrials.gov [Internet]. Bethesda (MD): National Library of Medicine (US). 2000- [22 April 2014].

70. Target Health Inc., UCSF Helen Diller Family Comprehensive Cancer Center; Weill Cornell Breast Center; Beth Israel Medical Center; Wake Forest University School of Medicine. In: ClinicalTrials.gov [Internet]. Bethesda (MD): National Library of Medicine (US). 2000- [22 April 2014].

71. Katsimbri P, Bamias A, Pavlidis N (2000) Prevention of chemotherapyinduced alopecia using an effective scalp cooling system. Eur J Cancer 36: 766-771.

72. Christodoulou C, Klouvas G, Efstathiou E, Zervakis D, Papazachariou E, et al. (2002) Effectiveness of the MSC cold cap system in the prevention of chemotherapy-induced alopecia. Oncology 62: 97-102.

73. Ridderheim M, Bjurgerg M, Gustavsson A (2003) Scalp hypothermia to prevent chemotherapy-induced alopecia is effective and safe: a pilot study of a new digitized scalp-cooling system used in 74 patients. Support Care Cancer 11: 371-377.

74. Auvinen PK, Mahonen UA, Soininen KM, Paananen PK, Ranta-Koponen $\mathrm{PH}$, et al. (2010) The effectiveness of a scalp cooling cap in prevention of chemotherapy-induced alopecia. Tumori 96: 271-275.

75. van den Hurk CJ, Mols F, Vingerhoets AJ, Breed WP (2010) Impact of alopecia and scalp cooling on the well-being of breast cancer patients. Psychooncology 19: 701-709.

76. Kargar M, Sarvestani RS, Khojasteh NH, Heidari MT (2011) Efficacy of penguin cap as scalp cooling system for prevention of alopecia in patients undergoing chemotherapy. J Adv Nurs 67: 2473-2477.
77. Betticher DC, Delmore G, Breitenstein U, Anchisi S, Zimmerli-Schwab B, et al. (2013). Efficacy and tolerability of two scalp cooling systems for the prevention of alopecia associated with docetaxel treatment. Support Care Cancer 21: 2565-2573.

78. van den Hurk CJ, van den Akker-van Marle ME, Breed WP, van de PollFranse LV, Nortier JW, et al. (2013) Impact of scalp cooling on chemotherapyinduced alopecia, wig use and hair growth of patients with cancer. Eur J Oncol Nurs 17: 536-540.

79. van den Hurk CJ, Breed WPM, Nortier JW (2012) Short post-infusion scalp cooling time in the prevention of docetaxel-induced alopecia. Support Care Cancer 20: 3255-3260.

80. van den Hurk CJ, Peerbooms M, van de Poll-Franse LV, Nortier JW, Coebergh JWW, et al. (2012) Scalp cooling for hair preservation and associated characteristics in 1411 chemotherapy patients - Results of the Dutch Scalp Cooling Registry. Acta Oncol 51: 497-504.

81. Witman G, Cadman E, Chen M (1981) Misuse of scalp hypothermia. Cancer Treat Rep 65: 507-508.

82. Fosberg SA (2001) Scalp cooling therapy and cytotoxic treatment. Lancet 357: 1134.

83. Christodoulou C, Tsakalos, Galani E, Skarlos DV (2006) Scalp metastases and scalp cooling for chemotherapy-induced alopecia prevention. Ann Onco 17: 350 .

84. Lemieux J, Amireault C, Provencher L, Maunsell E (2009) Incidence of scalp metastases in breast cancer: a retrospective cohort study in women who were offered scalp cooling. Breast Cancer Res Treat 118: 547-552.

85. Mols F, van den Hurk CJ, Vingerhoets AJJM, Breed WPM (2009) Scalp cooling to prevent chemotherapy-induced hair loss: practical and clinical considerations. Support Care Cancer 17: 181-189.

86. Granai CO, Frederickson H, Gajewski W, Goodman A, Goldstein A, et al. (1991) The use of minoxidil to attempt to prevent alopecia during chemotherapy for gynecologic malignancies. Eur J Gynaecol Oncol 12: 129132

87. Rodriguez R, Machiavelli M, Leone B, Romero A, Cuevas MA, et al. (1994) Minoxidil (Mx) as a prophylaxis of doxorubicin--induced alopecia. Ann Oncol 5: 769-770.

88. Duvic M, Lemak NA, Valero V, Hymes SR, Farmer KL, et al. (1996) A randomized trial of minoxidil in chemotherapy-induced alopecia. J Am Acad Dermatol 35: 74-78.

89. Hussein AM (1995) Protection against cytosine arabinoside-induced alopecia by minoxidil in a rat animal model. Int J Dermatol 34: 470-473.

90. Mori O, Uno H (1990) The effect of topical minoxidil on hair follicular cycles of rats. J Dermatol 17: 276-281.

91. Messenger AG, Rundegren J (2004). Minoxidil: mechanisms of action on hair growth. Br J Dermatol 150: 186-194.

92. Sredni B, Gal R, Cohen IJ, Dazard JE, Givol D, et al. (2004) Hair growth induction by the Tellurium immunomodulator AS101: association with delayed terminal differentiation of follicular keratinocytes and ras-dependent up-regulation of KGF expression. FASEB J 18: 400-402.

93. Hidalgo M, Rinaldi D, Medina G, Griffin T, Turner J, et al. (1999) A phase I trial of topical topitriol (calcitriol, 1,25-dihydroxyvitamin D3) to prevent chemotherapy-induced alopecia. Anticancer Drugs 10: 393-395.

94. Wat H, Dytoc M (2014) Off-label uses of topical vitamin d in dermatology: a systematic review. J Cutan Med Surg 18: 91-108.

95. Jimenez JJ, Yunis AA (1992) Protection from chemotherapy-induced alopecia by 1,25-dihydroxyvitamin D3. Cancer Res 52: 5123-5125.

96. Jimenez JJ, Yunis AA (1996) Vitamin D3 and chemotherapy-induced alopecia. Nutrition 12: 448-449.

97. Schilli MB, Paus R, Menrad A (1998) Reduction of intrafollicular apoptosis in chemotherapy-induced alopecia by topical calcitriol analogs. J Invest Dermatol 111: 598-604. 
98. Chen G, Balechle A, Nevins TD, Oh S, Harmon C, et al. (1998) Protection against cyclophosphamide-induced alopecia and inhibition of mammary tumor growth by topical 1,25-dihydroxyvitamin d3 in mice. Int J Cancer 75 303-309.

99. Hussein AM, Jimenez JJ, McCall CA, Yunis AA (1990) Protection from chemotherapy-induced alopecia in a rat model. Science 249: 1564-1566.

100. Wikramanayake TC, Amini S, Simon J, Mauro LM, Elgart GW, et al. (2012) A novel rat model for chemotherapy-induced alopecia. Clin Exp Dermatol 37 284-289.

101. Jimenez JJ, Roberts SM, Mejia J, Mauro LM, Munson JW, et al. (2008) Prevention of chemotherapy-induced alopecia in rodent models. Cell Stress Chaperones 13: 31-38.

102. Hussein AM (1991) Interleukin 1 protects against 1- $\beta-d-$ arabinofuranosylcytosine-induced alopecia in a rat animal model. Cancer Res 51: 3329-3330.

103. Jimenez JJ, Wong GHW, Yunis AA (1991) Interleukin 1 protects from cytosine arabinoside-induced alopecia in the rat model. FASEB J 5: 2456 2458.

104. Jimenez JJ, Haung HS, Yunis AA (1992) Treatment with ImuVert/N acetylcysteine protects rats from cyclophosphamide/cytarabine-induced alopecia. Cancer Invest 10: 271-276.

105. Hussein AM, Stuart A, Peters WP (1995) Protection against chemotherapyinduced alopecia by cyclosporin $\mathrm{A}$ in the newborn rat animal model. Dermatology 190: 192-196.

106. Maurer M, Handjiski B, Paus R (1997) Hair growth modulation by topical immunophilin ligands: induction of anagen, inhibition of massive catagen development, and relative protection from chemotherapy-induced alopecia. Am J Pathol 150: 1433-1441.

107. Jimenez JJ, Yunis AA (1992) Protection from 1-beta-D arabinofuranosylcytosine-induced alopecia by epidermal growth-factor and fibroblast growth-factor in the rat model. Cancer Res 52: 413-415.

108. Danilenko DM, Ring BD, Yanagihara D, Benson W, Wiemann B, et al. (1995) Keratinocyte growth factor is an important endogenous mediator of hair follicle growth, development, and differentiation. Normalization of the nu/ nu follicular differentiation defect and amelioration of chemotherapy-induced alopecia. Am J Pathol 147: 145-154.

109. Bichsel KJ, Gogia N, Malouff T, Pena Z, Forney E, et al. (2013) Role for the epidermal growth factor receptor in chemotherapy-induced alopecia. PLoS One 8: e69368

110. Paik SH, Yoon JS, Ryu HH, Lee JY, Shin CY, et al. (2013) Pretreatment of epidermal growth factor promotes primary hair recovery via the dystrophic anagen pathway after chemotherapy-induced alopecia. Exp Dermatol 22 496-499.

111. Gamady A, Koren R, Ron D, Liberman UA, Ravid A (2003) Vitamin D enhances mitogenesis mediated by keratinocyte growth factor receptor in keratinocytes. J Cell Biochem 89: 440-449.

112. Peters EM, Foitzik K, Paus R, Ray S, Holick MF (2001) A new strategy for modulating chemotherapy-induced alopecia, using PTH/PTHrP receptor agonist and antagonist. J Invest Dermatol 117: 173-178.

113. Katikaneni R, Ponnapakkam T, Suda H, Miyata S, Sakon J, et al. (2012) Treatment for chemotherapy-induced alopecia in mice using parathyroid hormone agonists and antagonists linked to a collagen binding domain. Int $\mathrm{J}$ Cancer 131: E813-821.

114. Katikaneni R, Ponnapakkam T, Matsushita O, Sakon J, Gensure R (2014) Treatment and prevention of chemotherapy-induced alopecia with PTHCBD, a collagen-targeted parathyroid hormone analog, in a non-depilated mouse model. Anticancer Drugs 25: 30-38.

115. Katikaneni R, Ponnapakkam T, Seymour A, Sakon J, Gensure R (2014)
Parathyroid hormone linked to a collagen binding domain promotes hair growth in a mouse model of chemotherapy-induced alopecia in a dosedependent manner. Anticancer Drugs.

116. Ohnemus U, Unalan M, Handjiski B, Paus R (2004) Topical estrogen accelerates hair regrowth in mice after chemotherapy-induced alopecia by favoring the dystrophic catagen response pathway to damage. J Invest Dermatol 122: 7-13.

117. Bodó E, van Beek N, Naumann V, Ohnemus U, Brzoska T, et al. (2009) Modulation of chemotherapy-induced human hair follicle damage by 17- $\beta$-estradiol and prednisolone: potential stimulators of normal hair regrowth by "dystrophic catagen" promotion? J Invest Dermatol 129: 506509

118.Zcharia E, Philp D, Edovitsky E, Aingorn H, Metzger S, et al. (2005) Heparanase regulates murine hair growth. Am J Pathol 166: 999-1008.

119. Wikramanayake TC, Villasante AC, Mauro LM, Nouri K, Schachner LA, et al. (2013) Low-level laser treatment accelerated hair regrowth in a rat mode of chemotherapy-induced alopecia. Lasers Med Sci 28: 701-706.

120. Plonka PM, Handjiski B, Popik M, Michalczyk D, Paus R (2005) Zinc as an ambivalent but potent modulator of murine hair growth in vivo - preliminary observations. Exp Dermatol 14: 844-853.

121. Sato N, Leopold PL, Crystal RG (2001) Effect of adenovirus-mediated expression of sonic hedgehog gene on hair regrowth in mice with chemotherapy-induced alopecia. J Natl Cancer Inst 93: 1858-1864.

122. Bohm M, Bodo E, Funk W, Paus R (2013) a-Melanocyte-stimulating hormone: a protective peptide against chemotherapy-induced hair follicle damage? Br J Dermatol 170: 956-960.

123. Takahata K, Tada M, Yazawa K, Tamaki $T$ (1999) Protection from chemotherapy-induced alopecia by docosahexaenoic acid. Lipids 34: S105.

124. Tsuda T, Ohmori Y, Muramatsu H, Hosaka Y, Takiguchi K, et al. (2001) Inhibitory effect of M50054, a novel inhibitor of apoptosis, on anti-Fasantibody-induced hepatitis and chemotherapy-induced alopecia. Eur J Pharmacol 433: 37-45.

125. Nakashima-Kamimura N, Nishimaki K, Mori T, Asoh S, Ohta S (2008) Prevention of chemotherapy-induced alopecia by the anti-death FNK protein. Life Sci 82: 218-225.

126. D'Agostini F, Bagnasco M, Giunciuglio D, Albini A, De Flora S (1998) Inhibition by oral $\mathrm{N}$-acetylcysteine of doxorubicin-induced clastogenicity and alopecia, and prevention of primary tumors and lung micrometastases in mice. Int J Oncol 13: 217-224.

127. Hagiwara S, Uchida T, Koga H, Inomata M, Yoshizumi F, et al. (2011) The a-lipoic acid derivative sodium zinc dihydrolipoylhistidinate reduces chemotherapy-induced alopecia in a rat model: a pilot study. Surg Today 41 693-697.

128. D'Agostini F, Fiallo P, Ghio M, De Flora S (2013) Chemoprevention of doxorubicin-induced alopecia in mice by dietary administration of L-cystine and vitamin B6. Arch Dermatol Res 305: 25-34.

129. Balsari A, Menard S, Colnaghi MI, Ghione M (1991) Anti-drug monoclonal antibodies antagonize toxic effect more than anti-tumor activity of doxorubicin. Int J Cancer 47: 889-892.

130. Haslam IS, Pitre A, Schuetz JD, Paus R (2013) Protection agains chemotherapy- induced alopecia: targeting ATP-binding cassette transporters in the hair follicle? Trends Pharmacol Sci 34: 599-604.

131. Frith $\mathrm{H}$, Harcourt D, Fussell A (2007) Anticipating an altered appearance: Women undergoing chemotherapy treatment for breast cancer. Eur $\mathrm{J}$ Oncol

\section{Copyright}

(c) 2014 Villasante AC, et al. This is an open access article distributed under the Creative Commons Attribution License, which permits unrestricted use, distribution, and reproduction in any medium, provided the original work is properly cited. 